\title{
LACLAU EN DEBATE: POSTMARXISMO, POPULISMO, MULTITUD Y ACONTECIMIENTO (ENTREVISTADO POR RicARDO CAMARGO)*
}

\author{
Laclau in debate: Post-Marxism, Populism, Multitude \\ and Event (Interviewed by Ricardo Camargo)
}

\section{ERNESTO LACLAU}

Department of Government, University of Essex, UK.

\begin{abstract}
RESUMEN
En esta entrevista Ernesto Laclau comienza haciendo un recorrido por su evolución intelectual, la que ha transitado desde un Marxismo latinoamericano hacia un postmarxismo con influencias Gramscianas y Lacanianas. En seguida, la entrevista se centra en el debate que Laclau ha venido sosteniendo con las nociones de Multitud y Acontecimiento desarrolladas por Toni Negri y Alain Badiou, respectivamente. Por último, la entrevista aborda las nociones de Populismo, Hegemonía y Contrahegemonía desarrolladas por Laclau en sus últimos trabajos, teniendo siempre como referencia explícita el acontecer político latinoamericano y en especial el actual proceso boliviano.
\end{abstract}

Palabras clave: Postmarxismo, populismo, multitud, acontecimiento, Ernesto Laclau.

\begin{abstract}
In this interview Ernesto Laclau begins by tracing his intellectual evolution, which has shifted from a Latin American Marxism to a post-Marxism with Gramscian and Lacanian influences. Thereafter, the interview addresses the debate that Laclau has been facing with the notions of Multitude and Event developed by Toni Negri and Alain Badiou respectively. Lastly, the interview discusses the notions of Populism, Hegemony and contra-Hegemony developed by Laclau in his late works, having always as an explicit reference the Latin-American political setting and particularly the current Bolivian process.
\end{abstract}

Key words: Post-Marxism, Populism, Multitude, Event, Ernesto Laclau.

* Entrevista sostenida en Londres, marzo de 2009, en el marco del proyecto de investigación posdoctoral Fondecyt N ${ }^{\circ} 3090028$, adscrito al Instituto de Humanidades, Universidad Diego Portales, Santiago-Chile. 


\section{HACIA UN POSTMARXISMO SIN APOLOGÍAS}

Ricardo Camargo - Profesor Ernesto Laclau, la verdad es que quisiera primero preguntarle acerca de la trayectoria histórica que tiene su reflexión actual sobre la política emancipadora que ha consignado recientemente en su último libro, La Razón Populista. ${ }^{1}$ Pero me interesa esa trayectoria histórica en el siguiente sentido, usted seguramente conoce el libro de Torfing...

Ernesto Laclau - ¿De quién?

Ricardo Camargo - New Theories Of Discourse: Laclau, Mouffe And Žižek de Jacob Torfing... ${ }^{2}$

Ernesto Laclau - ¡Ah! Jacob Torfing, sí, sí, él era estudiante mío de doctorado.

Ricardo Camargo - Sí, y él hace una especie de historiografía de su pensamiento dividiéndolo en tres etapas, una etapa gramsciana propiamente tal, una etapa postgramsciana, donde usted, según Torfing, habría abandonado el concepto de determinismo de la clase obrera y una tercera etapa más anclada ya en las tesis más lacanianas. Sin embargo, primero quiero preguntarle si está de acuerdo con esa radiografía y segundo si usted no ve en su propio desarrollo de pensamiento, quizás, alguna influencia más latinoamericana...

Ernesto Laclau - Bueno, mi pensamiento político en sus matrices fundamentales se formó en los años 60, allá en Argentina. Estaba en la dirigencia del Partido Socialista de la izquierda nacional ¿tú conoces a Jorge Abelardo Ramos? Bueno, él era el secretario general del partido, yo estaba en el buró político del partido, que éramos tres, Ramos, Jorge Nias, y yo, y yo era también el director del semanario del partido, que se llamaba Lucha Obrera. Ahora, esos fueron años muy importantes para crear una especie de matriz política. Yo nunca fui un marxista clásico en el sentido de que siempre traté de combinar el marxismo con algún otro tipo de cosa y en los años 60 las influencias intelectuales más importantes desde un punto de vista teórico fueron Althusser y Gramsci. Gramsci, el más importante. De ahí vino toda mi apreciación de lo nacional popular. Ahora, Althusser tenía ese famoso ensayo sobre "contradicciones y sobredeterminación", 3 en el cual decía que toda contradicción de clase está siempre sobredeterminada. Ahora esa idea de que una contradicción está sobredeterminada por otros elementos, bueno, cuajaba bien con todo el enfoque más bien de tipo gramsciano, y entonces ese fue el primer momento, y mi perspectiva política no ha variado demasiado desde aquel entonces.

El problema en Argentina en los años 60 era el resurgimiento del peronismo como fuerza histórica. Se da el proceso de lo que se llamó en esa época la nacionalización de las clases medias, porque toda la izquierda en Argentina se ha dividido entre una izquierda liberal y una izquierda nacional. Entonces la izquierda nacional era más de corte populista, la izquierda liberal era típicamente representada por el Partido Comunista argentino que era violentamente antiperonista todavía en esos años. Entonces era prácticamente imposible 
explicar la emergencia del movimiento de masas en Argentina simplemente en términos de lucha de clases, había que entender las identidades políticas en un sentido más amplio. Entonces, eso fue el comienzo; después, cuando vine a Europa, yo vine a Europa en el 69, fui primero tres años a Oxford a hacer mi doctorado y después me nombraron profesor en Essex. Yo cuando vine aquí a Europa pensaba que venía por tres años y todavía estoy. Lo que pasó es que después se complicó la situación política en la Argentina. Durante la dictadura no podía volver y ya cuando terminó el régimen militar habían pasado muchos años. De todos modos voy cada año a Argentina; ahora en mayo voy a estar seis semanas y ahí tenemos un centro de investigación en la Universidad de San Martín donde también da clases este chileno, cómo se llama, Manuel Antonio Garretón, y con él somos muy amigos. ${ }^{4}$ Bueno, entonces seguimos ahí y tenemos un grupo de investigación muy nutrido y así fue, pero una vez que vine a Europa entré en contacto con toda la tradición postestructuralista y eso se engarzaba bastante bien con el tipo de preocupación política que yo tenía en esos años, así que eso es en términos muy globales.

Ricardo Camargo - A propósito del tema histórico, y antes de entrar a los temas teóricos que me interesan, ya que soy chileno y que ha mencionado a Manuel Antonio Garretón, quería preguntarle ¿cuál fue su relación, si es que hubo alguna, con el proceso de renovación política ideológica que tuvo la izquierda latinoamericana, fundamentalmente en Chile, Argentina, Uruguay? En Chile principalmente lo que se conoció como la renovación del socialismo. Yo recuerdo un seminario que se cita mucho en Chile, un seminario de Morelia, donde usted presentó un paper en español que es como la base de su libro posterior en coautoría con Chatal Mouffe, Hegemonía y Estrategia Socialista. ${ }^{5}$

Ernesto Laclau - No me acuerdo de ese artículo, pero...

Ricardo Camargo - En Morelia, un artículo en español y que se cita, es muy citado en el proceso de renovación socialista chileno... ${ }^{6}$

Ernesto Laclau - Ajá.

Ricardo Camargo - ...como una fuente, como una perspectiva novedosa para entender los procesos políticos de la época, de ese momento y que, bueno, los sectores críticos lo leen como el primer punto de arranque de lo que se conoce como el postmarxismo. Yo no sé si hay algún vínculo más orgánico, o solamente influencia intelectual por parte de usted en estos procesos. ¿Usted tuvo alguna participación directa en algunos procesos de discusión con sectores tanto de la Argentina como en Chile en lo que se llamó la renovación?

Ernesto Laclau - En Chile muy poco. Yo viajé a Chile a finales de los años 60 y después fui de nuevo durante el período de Allende un par de veces. Después obviamente dejé de ir y ahora, de alguna manera, no ha habido demasiado contacto. Sin embargo, yo creo que la izquierda latinoamericana está dividida de nuevo de acuerdo a matrices bastante clásicas; por un lado, hay una izquierda populista, el epítome sería el chavismo y, por otro, 
hay una izquierda muy limitada en sus alcances renovadores que típicamente es lo que se da en Uruguay o en Chile, de alguna manera, más en Uruguay que en Chile, y el proceso Argentino está en un nivel intermedio pero tiende más hacia el polo populista. Yo creo que cuando uno piensa en el liberalismo y la democracia, uno tiene que darse cuenta de que las dos cosas no coincidían en sus orígenes. En Europa, a principios del siglo XIX, el liberalismo era un fórmula política perfectamente respetable, había existido desde fines del siglo XVII en Inglaterra y desde por lo menos la revolución de junio en Francia, pero por el otro lado democracia era un poco como populismo hoy día, era un término peyorativo que se le confundía con el gobierno de la turba, jacobinismo, todo este tipo de cosas, y tomó todo el proceso, largo proceso de revoluciones, contrarrevoluciones del siglo XIX, lograr que hubiera una especie de equilibrio estable entre liberalismo y democracia. De modo que uno habla hoy de regímenes liberal-democráticos como si fueran algo homogéneo, pero son internamente muy divididos.

Ahora yo creo que esa fusión entre liberalismo y democracia nunca se dio en América Latina de una manera perfecta. Uno tiene en América Latina el Estado liberal que fue el Estado que constituyen las oligarquías en la mitad del siglo XIX, pero que era muy poco democrático, porque eran de base clientelística. Entonces cuando empiezan las aspiraciones democráticas de las masas a expresarse, tienden a expresarse a través de moldes esencialmente no liberales. Fue el estado novo en Brasil, fue el peronismo en Argentina, el MNR en Bolivia. Pero lo que ocurre después que llegan las dictaduras duras de los años 60 a 80 es que ellas golpean igualmente la tradición liberal democrática y la tradición nacional populista. Entonces se crean las bases para una cierta convergencia de las dos. Hoy no hay regímenes populares en América Latina que postulen el abandono de las formas liberales de Estado, el problema es si se pone más el acento en un elemento articulador o en el otro. Por ejemplo, si usted ve en la reunión de presidentes de Mar del Plata, que tuvo lugar hace un par de años, allí la Argentina y Brasil impidieron que el proyecto del ALCA de Bush fuera aceptado y ahí, por ejemplo, Chile y Uruguay apoyaron al proyecto de Bush, en ese momento no estaba Bachelet todavía estaba Lagos, pero ahí es donde yo veo que puede haber una orientación americanista vía el MERCOSUR y puede haber una tendencia a la integración con los Estados Unidos más estrecha. Porque finalmente el NAFTA, y ese tipo de acuerdos, es la completa hegemonización de la economía mexicana por el poder imperial.

\section{REPENSANDO EL POPULISMO, ENFRENTANDO LA MULTITUD}

Ricardo Camargo - Lo que usted señala, profesor Ernesto Laclau, me permite también empezar a llevarlo a la discusión más teórica...

Ernesto Laclau - Sí.

Ricardo Camargo - ...en el siguiente sentido: usted ha señalado en su último libro, en La Razón Populista y otros artículos, sobre todo entrevistas de prensa, que no ve con desagrado o ve con simpatía, de alguna manera, los procesos que se producen por ejemplo en Venezuela, porque habría una expresión de una política populista de alguna forma, 
que usted defiende, usted desarrolla teóricamente como una forma de hacer política o como la expresión de la política propiamente tal ¿no? a diferencia de las nociones más peyorativas del populismo que se conocen en la teoría clásica. Eso es interesante porque ¿no sé si usted supo que hubo una conferencia teórica este fin de semana en Londres sobre la idea del comunismo organizada por Slavoj Žižek y Alain Badiou? ${ }^{7}$

Ernesto Laclau - Ah, sí.

Ricardo Camargo - Y donde estuvo presente también Jacques Rancière...

Ernesto Laclau - Sí, sí, supe de esa reunión.

Ricardo Camargo - A mí, estando en la conferencia y sabiendo que iba a entrevistarlo, me surgió la pregunta de qué hubiese planteado usted en esa conferencia respecto a la idea del comunismo entendiendo que, por ejemplo, Slavoj Žižek, al margen de sus posiciones teóricas frente a la idea del comunismo, termina finalmente teniendo una mirada positiva con lo que hoy día está haciendo Chávez y lo que está haciendo Evo Morales, y Toni Negri, paradojalmente, tiene una visión positiva también de lo que hace o lo que pudo llegar a hacer Lula en su gobierno; entonces pareciera que las confluencias políticas, las aplicaciones políticas de las perspectivas teóricas que están en disputa, terminan siendo muy similares, ¿no?

Ernesto Laclau - Bueno, Toni Negri estuvo en Bolivia, en realidad unas semanas antes; yo fui allá invitado por el gobierno boliviano y él había estado invitado un par de semanas antes y pese a los desacuerdos respecto a muchos aspectos, yo creo que en toda la cuestión latinoamericana ha tomado una buena posición, Negri, y Michael Hardt también, que está más todavía ligado a la cuestión latinoamericana que Toni; pero bueno, la posición de Žižek es otra cosa completamente distinta y ahí yo no veo un pensamiento político de ningún tipo, es una especie de discurso frenético sin distancia. El discurso de Badiou es mucho más interesante. Ahora vamos a tener una conferencia en Buenos Aires donde lo hemos invitado y yo estoy en desacuerdo con muchas cosas de las que él dice pero, de otro lado, él trata de superar el clasismo inveterado de la izquierda, como de alguna manera Hardt y Negri también tratan de hacerlo.

Ricardo Camargo - Quizás entrando en el debate que usted tiene primero con Negri y Hardt, dejando a Slavoj Žižek aparte por el momento, una de las cosas que a mí me llama la atención, que es algo que salió a propósito en la conferencia del fin de semana, la afirmación muy fuerte, muy marcadora que hace Toni Negri de que hoy día no es posible sostener un outsider, o un exterior al capitalismo propiamente tal, por lo que...

Ernesto Laclau - Pero ¿él no estaba en la conferencia, Negri?

Ricardo Camargo - ... ¿En la conferencia del fin de semana?, sí.

Ernesto Laclau - ¿Él estaba? ¿Estaba Negri?

"On the Idea of Communism's conference", tuvo lugar entre el 13 y el 15 de marzo de 2009 en el Logan Hall, Institute of Education, University of London. Participaron: Judith Balso, Alain Badiou, Bruno Bosteels, Terry Eagleton, Peter Hallward, Michael Hardt, Toni Negri, Jacques Rancière, Alessandro Russo, Alberto Toscano, Gianni Vattimo y Slavoj Žižek, véase http:/ / www.bbk.ac.uk/bih/activities/ideaofcommunism 
Ricardo Camargo - Sí, estaba Negri y estaba Hardt también; estaban los dos, pero expusieron en paneles distintos. Entonces esta tesis teórica que ellos sostienen de que no es posible hoy día asumir ningún "exterior" al capitalismo, más sería el propio capitalismo el que estaría generando sus condiciones de destrucción y de generación de un sujeto inmanente como sería la multitud ¿no?, usted ha criticado esa tesis...

Ernesto Laclau - Sí, pero no por el hecho de la interioridad; con eso yo estaría más bien de acuerdo. La he criticado porque pienso que ahí hay una evacuación del momento político, es decir, ellos sostienen, bueno hay que ver que Negri viene de la tradición del operarismo italiano. El operarismo era una reacción frente a la hegemonía del partido comunista italiano que había insistido mucho en el momento de la unificación política. Para Gramsci los sujetos sociales no son las clases, son lo que llama voluntades colectivas que es la articulación política de una serie de elementos heterogéneos. Por ejemplo, hubo todo un debate al final de la guerra acerca de la estrategia de constitución del comunismo en Italia. Entonces ahí hubo dos tesis, una tesis que era obrerista pura, que decía bueno, el país está fragmentado entre el norte industrial y el sur agrario, nosotros somos el partido de la clase obrera, tenemos que ser el partido del norte industrial. Y la otra posición que era la de la línea más gramsciana que finalmente se impuso porque Palmiro Togliatti, que era el secretario general del partido, la apoyaba y entonces allí ellos decían no, vamos a crear también la hegemonía del partido en el sur, y ¿cómo si la clase obrera es tan débil?, bueno vamos a transformar los locales del partido y los sindicatos en los puntos de aglutinación de una serie de luchas de distinto tipo, las luchas contra el problema del agua, las luchas contra la mafia, las cooperativas escolares, etcétera, y de esa manera, a través de esa mediación política vamos a construir sujetos de nuevo tipo. Y a ellos les fue bastante bien, en realidad fue una fuerza democratizadora enorme de la sociedad italiana el partido comunista, durante los años 40 y 50 y hasta mediados de los 60 y después empezó un nuevo tipo de movilización y para eso ya el partido no tenía respuesta. Primero estaban las huelgas salvajes que pasaban por encima de la organización sindical y la organización sindical era el meollo mismo del poder del partido comunista en Italia. Después estuvieron las movilizaciones estudiantiles alrededor del 68 que fueron de nuevo tipo y que también el partido las vio con mucha desconfianza. $Y$ después fue el movimiento feminista que en Italia no fue como en el mundo Anglosajón una cosa de intelectuales, fue un movimiento masivo, pero con un cierto tipo de demandas que era difícil para el Partido Comunista asimilarlo, por ejemplo, una de las consignas era "i copulación sin penetración!" No había forma de que el partido comunista fuera a apoyar algo así. Y entonces empezaron a desarrollarse formas autónomas de lucha que insistían en que cada lucha aislada, sin necesidad de construir una convergencia política, iba a conducir a una confrontación más global. Ahí es donde yo empiezo a estar en desacuerdo. Estoy de acuerdo en que la forma partido ya no puede ser la forma central de mediación que el socialismo clásico le atribuía, pero por otro lado me parece que la falta total de coordinación tampoco es una solución política, y la idea de multitud es la idea de un todo no estructurado en el cual distintas formas de antagonismos empiezan a proliferar. Ahora, yo hasta la mitad del argumento estoy de acuerdo, es decir, los antagonismos son mucho más complejos que lo que la teoría marxista clásica presuponía, hay muchos puntos de ruptura, luchas antiinstitucionales, 
todos los fenómenos de la globalización, etcétera. Pero lo que me parece es lo importante es experimentar con nuevas formas de articulación, no con el abandono total de la categoría de articulación, y ahí es donde empiezan las perspectivas nuestras a divergir.

Ricardo Camargo - Sin embargo, en la reflexión de Negri...

Ernesto Laclau - ¿En qué idioma habló él?

Ricardo Camargo - Habló en italiano.

Ernesto Laclau - ¡Ah!

Ricardo Camargo - Con una alumna que le traducía...

Ernesto Laclau - ¿Simultáneamente...?

Ricardo Camargo - Posteriormente optó porque la alumna le leyera el paper no más, porque se hacía confuso. En el paper Negri hacía la siguiente acotación que me parece interesante, porque ciertamente el déficit de, como usted lo señala, plantear un conjunto de luchas no articuladas es precisamente eso, que no logran articularse y que no logran convertirse en política propiamente tal, si lo entendemos como lo señala usted como un conjunto de articulación de demandas ¿no? con las lógicas que usted ha construido en sus textos. Sin embargo, si nosotros entendemos que la articulación de demandas muchas veces se da como articulación de demandas contra una institucionalidad, la pregunta que cabría ahí y que de alguna manera entiendo yo que el esfuerzo de la teoría de Negri trata de dar cuenta es ¿cómo logramos, no que se produzca una articulación y por tanto una lucha política, sino cómo esta articulación no queda subsumida en una institucionalidad que le da cabida y que termina disciplinando, de alguna manera, esa articulación que surge en primer momento, potencialmente, incluso actualmente, como una expresión política nueva, pero termina subsumida en el sistema político imperante o en el régimen político o en el orden político?

Ernesto Laclau - Sí, bueno, eso obviamente es como decía Lenin, caminar entre precipicios. Por un lado la excesiva institucionalización lleva a la fosilización de los movimientos, 1914 y la social democracia europea fueron el testimonio. Por el otro lado, la total falta de articulación lleva a la impotencia política. Entonces no hay, me parece, cuadratura del círculo que estos dos peligros de signo opuesto los pueda engarzar, hay simplemente que trabajar por equilibrios que son siempre pragmáticos. Pero por ejemplo Badiou tiene una teoría de exterioridad total que yo no comparto, pero para él, por ejemplo, los sans papiers como los llaman en Francia, los inmigrantes que no tiene un estatus legal, sin embargo están incorporados al mercado de trabajo, bueno, es una situación de exterioridad radical, pero esa misma exterioridad total lleva a la impotencia de este tipo de movimientos. Uno tiene que estar con un pie adentro y un pie afuera del sistema, me parece.

\section{BADIOU Y LOS DÉFICITS DEL ACONTECIMIENTO}

Ricardo Camargo - A propósito de ese tema en específico y metiendo a Alain Badiou a la discusión. Habla Badiou, defiende y defendió en sus escritos más polémicos quizás y también en esta conferencia la tesis de, como usted señala, generar espacios que estén a 
distancia del Estado, tesis que además fue ratificada por Toni Negri que define la acción política y la acción política comunista que es a la que se estaba refiriendo en ese momento, como contraria o como opuesta al Estado. Pero Badiou matiza esta postura señalando que se trata de una distancia al Estado, que es parecida a la terminología que usa Simon Critchley en su libro Infinitely Demanding, ${ }^{8}$ referida específicamente a construir un proceso de distancia al Estado. El problema con esta tesis es ¿qué significa la distancia al Estado? y si es posible tener una distancia al Estado que no esté de alguna manera relacionada con el Estado en términos políticos.

Ernesto Laclau - Bueno, incluso me parece que la gente que más está por la tesis de la sustracción respecto al poder del Estado, no la aplica coherentemente en esa línea. Por ejemplo, ¿qué sentido tendría una movilización por la despenalización del aborto si no es conseguir que cambie la legislación de una cierta manera?, o sea que los mismos movimientos contestatarios plantean objetivos que tienen que pasar por la mediación estatal. Por eso me parece que una teoría de la hegemonía es la teoría de la construcción de formas estatales nuevas, no es simplemente la oposición completa al poder del Estado, eso sería bakuninismo en el sentido más clásico.

Ricardo Camargo - Usted no le reconoce, por tanto, en ese punto, en el punto que usted señalaba anteriormente, el punto problemático de caminar entre precipicios como se refería usted, del dilema entre la necesidad de articular demandas, incluso contra la institucionalidad del Estado, versus la posibilidad permanente y cierta de quedar subsumido en la lógica dominante del Estado, ¿no le reconoce ninguna validez teórica a la tesis, por ejemplo, a la tesis del Acontecimiento de Badiou?

Ernesto Laclau - No, el Acontecimiento yo estoy muy de acuerdo con esto, lo que pasa es que el Acontecimiento me parece que es menos apocalíptico que lo que plantea Badiou, por ejemplo una categoría central en el análisis de Badiou es lo que llama conexión y desconexión. Uno tiene el Acontecimiento que es aquello que no es subsumible a la situación, hasta ahí, yo estoy de acuerdo con todo el análisis, la centralidad que damos a la categoría de antagonismo significa exterioridad en el sentido radical. Pero después él tiene que explicar cómo a partir de este acontecimiento originario se sigue una línea estratégica coherente. Entonces ahí él habla de conexión y desconexión, es decir, a partir del Acontecimiento empieza una práctica de conexión por la cual los elementos que eran exteriores al Acontecimiento empiezan a ser interiorizados. Ahora, si eso se plantea en esos términos, ¿en qué medida el acontecimiento sigue siendo el mismo Acontecimiento originario? Esto es, cada una de estas adiciones que son típicas de una política hegemónica ¿no modifica la naturaleza del Acontecimiento? Y ahí es donde viene, me parece, el problema que tú planteabas antes, es decir, estas conexiones sucesivas pueden llevar a la fagocitación del Acontecimiento originario por un sistema que amplía un poco sus bases, pero que sigue siendo fundamentalmente ese sistema, entonces ese peligro está allí. Pero todas estas lógicas yo creo que van a ser cada vez más importantes, por ejemplo, si tú piensas un fenómeno como el de la 
Argentina, en Argentina vino la crisis del 2001, recuerda la crisis económica cuando el país casi colapsó. En ese momento entonces empieza a haber movilizaciones de todo tipo de sectores que nunca habían estado movilizados antes: las tomas de fábricas, las formas de autogestión, las organizaciones barriales, libres del sur, barrios de pie, todo este tipo de cuestiones y entonces sin embargo ellos dicen nosotros estamos en una relación de exterioridad total respecto al Estado, el lema era "que se vayan todos". Ahora el problema está en que si se van todos siempre se va a quedar uno y el uno que se queda, sino ha sido elegido por nadie no va a ser necesariamente el mejor. O sea que lo que ocurre a partir de ese momento es que se llega a las elecciones del 2003 y con una bajísima participación popular en las elecciones, porque había una especie de desencanto total respecto al sistema político. Néstor Kirchner gana las elecciones con el 15\% de los votos, entonces las cosas salieron bien porque, por uno de esos avatares de la política peronista, el que fue elegido fue Kirchner que tenía un programa coherente y de izquierda y entonces allí vienen las dos, digamos, presiones: por un lado había sectores en estas movilizaciones que se negaban a tener cualquier compromiso con el poder del Estado y, por otro, estaban los que desde el poder del Estado querían reprimir. Ahora, Kirchner se negó sistemáticamente a reprimir. El resultado fue que se había dado una enorme movilización horizontal de la protesta social, pero no se traducía verticalmente a nivel del sistema político y ahí hay un déficit que no ha sido completamente sanado. Kirchner tuvo una política de incorporación de muchas de estas demandas al sistema político. El sistema político es definitivamente más democrático hoy gracias a esto, pero el proceso está muy lejos de ser transparente. Respecto a la ruptura con el pasado dictatorial, ésta fue incompleta. Toda esa idea de la reconciliación que, por ejemplo, en Chile la gente insistía tanto, jamás el kirchnerismo la convalidó.

\section{BOLIVIA: HEGEMONÍA Y CONTRAHEGEMONÍA}

Ricardo Camargo - Pero haciendo un contrapunto quizás con Bolivia y mencionó a Chile...

\section{Ernesto Laclau - Sí.}

Ricardo Camargo - ... porque en el caso chileno la reconciliación o la tesis de la reconciliación que en un primer momento funciona como el discurso político para poder darle una legitimidad, moral incluso, a la democracia, termina en los últimos años funcionando como una premisa defendida por muchos sectores, incluso intelectuales, de transparencia en el sentido más teórico, en el sentido de no a los conflictos, de no a los antagonismos. Pretendemos estar todos reconciliados en una sociedad nueva y construir un país reconciliado sin conflictos, o sea, termina usada en su anverso, para precisamente generar un consenso sin antagonismos como se planteaba.

Ernesto Laclau - En el modelo Argentino fue el opuesto, profundizar el momento de antagonismo respecto al pasado dictatorial... 
Ricardo Camargo - Exactamente. Y ahí la pregunta, aquí viene el contrapunto. Es interesante observar lo que pasa en Bolivia, en este caso, y hay una reflexión muy potente que está haciendo García Linera...

Ernesto Laclau - Sí, yo estuve comiendo con él allá en La Paz. Él fue quien me invitó allá a Bolivia.

Ricardo Camargo - Él acaba de publicar un libro por CLACSO que se llama La Potencia Plebey $a^{9}$ donde hace una reflexión en donde precisamente a partir de estos temas él señala, porque su reflexión es muy franca, él dice, bueno, nosotros siempre peleamos contra el Estado, y ahora estamos dentro del Estado. Pero, agrega García Linera, ¿cómo hacer para, estando dentro del Estado, seguir debilitando el Estado y de alguna manera, generando un movimiento popular? Entonces su reflexión lo lleva, producto de su práctica, a plantearse que es posible generar políticas antiestatales desde el Estado. Antiestatales porque son populares, son de creación de sujeto popular incluso desde el Estado. Es algo absolutamente original, me parece a mí, en la reflexión política emancipadora.

Ernesto Laclau - Él está muy bien políticamente. Yo estoy de acuerdo bastante con la línea que él está empujando y Evo Morales está haciendo las cosas bien. La cuestión es que ahí con el regionalismo extremo es difícil ver qué es lo que va a ocurrir. Hay zonas en las cuales simplemente no hay la posibilidad de que haya alguien contra Evo. Había una anécdota que Pablo Stefanoni, que es un periodista argentino que vive en Bolivia desde hace años, quien contaba que había ido a una zona que hay en el altiplano donde toda la población de la aldea era absolutamente pro Evo. Y entonces uno dijo: "En las últimas elecciones hubo un voto por el Tuto Quiroga y nosotros queremos saber quién fue ese que votó por Quiroga porque no queremos tener traidores entre nosotros". Ahora cuando el clima es así, te das cuenta de que son dos países. No hay posibilidad de mediación. No estamos en Iowa con los votantes eligiendo candidatos entre varias opciones.

Ricardo Camargo - ¿Cómo se observa ese proceso, quedándonos ahí, desde las premisas teóricas que usted señala? Por ejemplo, la premisa teórica en donde usted postula que la 'sociedad no existe'. Pero, sin embargo si bien es cierto la cerradura de la sociedad no es posible, pero sí es posible en alguna medida porque es necesaria, porque si no, hay implosiones sociales, por tanto tiene que haber algún nivel de sutura, pero pensar que esa sociedad se va a cerrar en términos de armonizar completamente, es una contradicción, es imposible. ¿Cómo se aplicaría, cómo ve usted esas premisas teóricas en procesos reales como el de Bolivia en donde al parecer los antagonismos están siendo impulsados desde el Estado, no hacia el Estado? El Estado está dentro de una parte del antagonismo.

Ernesto Laclau - Y, bueno, lo que pasa es que ahí hay varios Estados. Santa Cruz es un Estado dentro del Estado y es tan centralista en su política dentro de su zona como lo es Evo dentro de la suya. La cuestión es que para poder tener una política hegemónica lo que se necesita son sectores heterogéneos que no estén anclados ahí como los Capuletos y los Montescos a una oposición feroz, y yo no sé realmente cómo esa situación se va a ir 
solucionando. Ahora se ha calmado un poco la cosa en los últimos meses después de que llegaron a este tipo de acuerdo, finalmente la Constitución va a pasar y veremos pero, no hay mucho room for maneuver, ¿no?

Ricardo Camargo - Por lo tanto, ¿el proceso Boliviano, usted no lo lee como un proceso de construcción de hegemonía desde el Estado?

Ernesto Laclau - Sí, pero lo que pasa es que ahí las fronteras son mucho más rígidas que en otros casos. Por ejemplo, si tú piensas en Argentina, ahí tú tienes una sociedad muy heterogénea pero de otro lado, socialmente, bastante homogénea, porque lo que pasa alrededor de los tres grandes centros industriales que son Rosario, Córdoba y Buenos Aires, donde vive el $80 \%$ de la población del país es lo que da una cierta centralidad a cualquier proceso popular radical. Si uno tiene una situación de extrema regionalización, en ese caso, esa situación es mucho más difícil. Por ejemplo, en el pasado el Varguismo y el Peronismo, si tú comparas, Perón era el jefe de un movimiento homogéneo, por este fenómeno que decíamos antes, pero Getúlio Vargas se encontraba con un país absolutamente regionalizado y el poder era local y el Estado nacional era sumamente débil. Entonces él tenía que ser el articulador de fuerzas muy dispares y su populismo era un populismo mucho más débil en última instancia. El único que se trató de largar a hacer un fenómeno de tipo peronista en Brasil fue João Goulart, y así le fue, se quedó absolutamente aislado en su enclave.

\section{LÓGICA POPULISTA Y EMANCIPACIÓN}

Ricardo Camargo - Entrando a la última parte, el tema del populismo, que ha sido la 'razón populista' que usted ha desarrollado en sus últimos trabajos, pareciera haber tenido bastante acogida en Latinoamérica, sobre todo por los procesos que se están dando allí, catalogados como populistas por distintos sectores, con distintas intenciones, distintos efectos. Sin embargo, si uno revisa no solamente la actualidad de Latinoamérica, sino la historia de Latinoamérica, uno se encuentra con regímenes populistas desde hace mucho tiempo, digamos, y si uno toma en serio sus tesis, como yo creo que hay que tomarlas en serio, uno ve que el populismo es una forma de hacer política y probablemente la forma de hacer política que ha sido más prioritaria o más mayoritaria en Latinoamérica, sin embargo eso me lleva a la pregunta de ¿cómo conciliar esa lógica de hacer política, la lógica populista, con una lógica emancipadora, con una lógica que toma partido con los valores de los dominados y no solamente de las estructuras de la política? Lo que quiero decir, el populismo, como usted ha señalado, se puede construir desde sectores progresistas de la sociedad o desde sectores...

Ernesto Laclau - ...Absolutamente reaccionarios...

Ricardo Camargo - O reaccionarios, exacto. ¿Cómo, en términos teóricos, por tanto, postular una lógica populista que garantice o dé garantía de ser emancipadora? ¿O eso no es posible en su lógica, en su teoría?

Ernesto Laclau - Yo creo que sí, pero el problema es que un régimen no puede ser simplemente populista. Tiene que ser al mismo tiempo otras cosas, por los motivos que tú 
dices, puede haber un populismo... yo creo que el maoísmo es una forma de populismo, pero el fascismo también lo era, o sea que el populismo no define la ideología de un movimiento, lo que define es una forma de construcción de lo político que procede a través de la división dicotómica de la sociedad en dos campos, entonces, uno puede tener o bien institucionalismo, que sería lo opuesto; es decir, las demandas no se agrupan a través de foros matriciales, sino que tienden a plantearse separadamente las unas de las otras y, de otro lado, la otra posición extrema sería la posición populista, es decir, un discurso que divide a la sociedad entre dos campos, los de arriba y los de abajo.

Ahora, yo creo que una política emancipadora tiene que tener una dimensión populista necesariamente, pero tiene que además definirse por los contenidos de esa política, no simplemente por el hecho de ser populista. Por ejemplo, en el año 1945 Perón dice que hay una opción solamente para la Argentina, Spruille Braden, el embajador norteamericano, o Perón. Entonces hay sólo dos posiciones discursivas de donde uno puede hablar y todos los contenidos de la sociedad se tienden a distribuir alrededor de estos dos polos. En cambio, en un discurso institucionalista, los momentos de legitimidad tienden a esparcirse y la sociedad parece menos dividida de una manera polar. Ahora, yo creo que todo régimen viable tiene que combinar de alguna manera en distintas proporciones el institucionalismo y el populismo. Como te decía antes, me parece que los regímenes uruguayos y chilenos actuales se han inclinado demasiado hacia el lado puramente institucionalista y el momento de confrontación no está demasiado presente, pero, de otro lado, un populismo extremo en el cual no hubiera ninguna forma de institucionalidad mínima tampoco es una solución. Eso lleva puramente al caos social. Los jacobinos tenían la idea de que podían dividir al pueblo radicalmente del antiguo régimen y empezaron a cortar más y más cabezas hasta que al final se encontraron que habían llegado a una especie de vacío total. Incluso regímenes como el peronismo, el peronismo histórico, el de los años ' 40 y ' 50 , trataban de pasar a una cierta, digamos, institucionalización. Al principio la figura típica es el descamisado, el equivalente argentino del sans-culottes, y había un monumento al descamisado en el centro de Buenos Aires. Después la figura del descamisado empieza cada vez más a desaparecer y, en la última etapa, el peronismo empieza a hablar de la comunidad organizada, o sea que se daban cuenta de la necesidad de ir institucionalizando el proceso, de alguna manera. Yo me acuerdo que Perón me mandó una carta en esa época en la que estábamos con la de la izquierda nacional; bueno, él mandaba cartas diciendo cosas totalmente distintas a unos y a otros, dependiendo del color de las ideologías. Bueno, porque se daba cuenta de que estaba escribiéndole a un izquierdista. Entonces me dijo que las revoluciones pasan por tres etapas, la primera etapa es la preparación ideológica, es decir Lenin, la segunda etapa es la toma del poder, es decir Trotsky, y la tercera etapa es la institucionalización de la revolución, es decir Stalin, y decía que la revolución peronista tenía que pasar de la segunda a la tercera etapa. Ahora, lo que no se daba cuenta era que no estaba en el poder y que tenía que volver a tomar el poder y que eso estaba desencadenando fuerzas que no podía controlar. Yo contaba un poco este proceso en el libro sobre el populismo.

Ricardo Camargo - Sí, lo recuerdo, pero escuchándolo me surge la siguiente pregunta que no la he escuchado todavía en su relato, digamos, hay una tensión entre la forma populista de la política y la ideología emancipadora, llamémosla así ¿no? y el tercer factor 
que no lo encuentro todavía es ¿cómo está inscrita esa forma populista y esa ideología emancipadora en un contexto capitalista?

Ernesto Laclau - Bueno ahí es donde viene toda la discusión que se está teniendo hoy día con gente como Negri, gente como Badiou...

Ricardo Camargo - ¿Cómo ve usted esa discusión?

Ernesto Laclau - Bueno, yo lo veo en la forma que te dije, yo no estoy a favor de decir "hay que estar completamente fuera del Estado, del terreno del Estado", porque de hecho es imposible, eso sería una impotencia total. De otro lado, tampoco me parece que la política pueda ser puramente socialdemócrata completamente interna al momento Estatal. Ahí es donde me parece que hay que combinar la dimensión vertical que es la influencia sobre el Estado y la dimensión horizontal que es el desarrollo de la protesta social. Yo creo que, por ejemplo, en Venezuela que es donde el proceso ha logrado una cierta forma de equilibrio, el régimen es más sólido ahora que lo que era hace un par de años. Pero ahí tú vez, por un lado, que sin movilización popular autónoma el golpe de Estado del 2002 hubiera triunfado, ahí fue la gente que salió a la calle y volvió a colocar a Chávez en el poder. Pero, por otro lado, sin acción del Estado, sin Chávez tampoco el proceso hubiera podido desarrollarse. Hay que ver lo que pasa ahí. Había zonas en Venezuela... ¿Tú conoces Venezuela?

\section{Ricardo Camargo - No.}

Ernesto Laclau - Bueno, había zonas en donde el médico más cercano estaba a tres días de distancia ¿Te imaginas? Se moría la gente como moscas. Ahora hay 30 mil técnicos cubanos que son sobre todo maestros y médicos, y los médicos van a vivir a estas zonas con peligro para sus vidas, porque son zonas donde la seguridad es mínima, han matado a unos cuántos, pero de otra manera esto da una confianza a la gente que empieza a movilizarse de forma autónoma, las misiones funcionan bastante bien, pero de otro lado la acción a nivel del aparato central es decisiva, sin eso no hubiera pasado absolutamente nada. O sea que me parece que no hay que unilateralizar los dos niveles.

Ricardo Camargo - Estoy de acuerdo y me queda muy claro su apreciación sobre el Estado, pero mi pregunta también va respecto a su apreciación sobre el capitalismo en el siguiente sentido: ¿tiene sentido hablar de estos mismos esquemas que usted plantea, de la forma populista de hacer política y una ideología emancipadora, hacer una ideología y una forma populista de ideología emancipadora anticapitalista hoy día y en qué sentido?

Ernesto Laclau - Bueno, hay formas de movilización que definitivamente son anticapitalistas. Ahora, el anticapitalismo no puede ser un denominador común total, por ejemplo, la forma en que se va a gestar la solución de la crisis financiera mundial puede tener formas más de izquierda o más de derecha y las de izquierda van a pasar por la regulación frente a la ideología del libre cambio y la regulación va a tener que ser una regulación estatal. Lo importante es que esa regulación estatal se haga con participación democrática, por supuesto, pero hay un momento estatista ahí que es decisivo. ¿Tú te acuerdas de aquel viejo libro de Hernán Ramírez Necochea, sobre la revolución del 1890 ?

Ricardo Camargo - Del 1891. 
Ernesto Laclau - Del 1891, sí, bueno ahí estaba perfectamente claro. La oligarquía chilena era totalmente antiestatista y Balmaceda era el que tenía la idea de un fin desarrollista estatal.

Ricardo Camargo - Muy bien, muchas gracias,

Ernesto Laclau - Gracias.

\section{REFERENCIAS}

Althusser, Louis. 1970. “Contradicción y sobredeterminación (notas para una investigación)". En Louis Althusser, La Revolución Teórica de Marx, México: Siglo XXI Editores, pp. 71-106 (Traducción: Marta Harnecker) t.or.: Pour Marx, Librairie François Maspero, París 1965).

Critchley, Simon. 2007. Infinitely demanding: Ethics of Commitment, Politics of Resistance. London: Verso.

García Linera, Álvaro. 2008. La Potencia Plebeya, Acción colectiva e identidades indígenas, obreras y populares en Bolivia. Buenos Aires: Colección Clacso Coediciones Clacso-Prometeo. Disponible on-line: http:// bibliotecavirtual.clacso.org.ar/ar/libros/coedicion/glinera.

Laclau, Ernesto. 1980. "Tesis acerca de la forma hegemónica de la política", paper presentado en el Seminario 'Hegemonía y Alternativas Populares en América Latina', Morelia, México.

Laclau, Ernesto. 2005. La Razón Populista. Buenos Aires y México: Fondo de Cultura Económica.

Laclau, Ernesto y Chantal Mouffe. 1985. Hegemony and Socialist Strategy: Towards a Radical Democratic Politics. London: Verso.

Torfing, Jacob. 1999. New Theories of Discourse, Laclau, Mouffe and Žižek. Oxford: Blackwell Publishers Ltd.

Ricardo Camargo es Doctor en Filosofía (Teoría Política) de la University of Sheffield, Inglaterra, Abogado y Magíster en Ciencia Política de la Universidad de Chile, Master of Art de la University of Otago, New Zealand. Actualmente, es investigador adjunto en el Instituto de Humanidades de la Universidad Diego Portales, Santiago-Chile y Becario Postdoctoral Fondecyt. Sus áreas de investigación son: la crítica de la ideología, nuevas concepciones de la política emancipadora y la política chilena. Entre sus últimas publicaciones destacan "The Critique of Ideology Revisited: A Žižekian Appraisal of Habermas's Communicative Rationality" (Contemporary Political Theory 2008) [ricardo.camargo@udp.cl]

Ernesto Laclau es Profesor Titular de Política y por muchos años Director del Programa Doctoral en Análisis de Discurso e Ideología en la University of Essex. Actualmente es también Director Honorario del Centro de Estudios del Discurso y las Identidades Sociopolítica (CEDIS) de la Universidad Nacional de San Martín. Es autor de numerosos libros entre los que se destacan Política e ideología en la teoría marxista: capitalismo, fascismo, populismo; New Reflections on the Revolution of our Time; Emancipación y diferencia; y recientemente La Razón Populista. Coautor junto con Chantal Mouffe del influyente texto Hegemonía y estrategia socialista; y con Butler y Žižek del libro de debate Contingencia, hegemonía, universalidad. Sus investigaciones actuales son la teoría política en perspectiva comparada, la construcción discursiva de los antagonismos sociales, la deconstrucción y la política. 